\title{
Review: support interventions reduce cessation of breast feeding before 2 months
}

\author{
Sikorski J, Renfrew MJ. Support for breastfeeding mothers. (Cochrane Review, latest version 30 Jun 1998.) In: Cochrane Library. \\ Oxford: Update Software.
}

\section{Question}

Does extra support for mothers who wish to breast feed reduce early cessation of breast feeding?

\section{Data sources}

Studies were identified by searching the Pregnancy and Childbirth Collaborative Review Group Specialised Register of Controlled Trials, the Cochrane Clinical Trials/Central Register, Medline (from 1993), Embase/Excerpta Medica (from 1980), CINAHL, and the English National Board Health Care Database. The Midwives Information and Resource Service quarterly digest was handsearched from 1991, secondary references were scanned, and experts were contacted.

\section{Study selection}

Randomised and quasi-randomised trials of postnatal interventions that provided supplementary support from professionals or volunteers to facilitate continued breast feeding were included. Interventions that were primarily educational or occurred only in the antenatal period were excluded.

\section{Data extraction}

Data were extracted on country, setting, participants, design, randomisation procedure, intervention, follow up, withdrawals, dropouts, blinding of assessors, and outcome measures. Main outcome was cessation of breast feeding at 2,3,4, and 6 months. Methodological quality of studies was assessed.

\section{Main results}

13 studies were identified; 2 studies reporting outcomes other than breast feeding duration were excluded. Support interventions reduced cessation of any breast feeding ( 5 studies) and cessation of exclusive breast feeding before 2 months ( 2 studies) (table). Based on the number needed to treat in the table, 10 women would need to be provided with support to ensure that 1 additional mother breast fed her infant until 2 months of age. Groups did not differ for cessation of any breast feeding before 3,4 , and 6 months. Interventions using primarily face to face contact were effective (5 studies), whereas those using telephone contact were not (4 studies) (table).

\section{Conclusions}

Breast feeding support reduces cessation of exclusive or any breast feeding before 2 months compared with usual care. Interventions that use primarily face to face contact are effective, whereas those using telephone contact are not.

Support v usual care for reducing breast feeding (BF) cessation*

\begin{tabular}{lcccc}
\hline & \multicolumn{2}{c}{ Weighted event rates } & & \\
\cline { 2 - 3 } Outcomes & Support & Usual care & RRR (95\% CI) & NNT (CI) \\
\hline Cessation of: & & & & \\
$\quad \begin{array}{l}\text { Any BF before 2 mo } \\
\text { Exclusive BF before 2 mo }\end{array}$ & $51.7 \%$ & $62.1 \%$ & $17 \%(4$ to 28$)$ & $10(6$ to 44) \\
$\begin{array}{l}\text { Cessation at last assess- } \\
\text { ment up to 6 months: }\end{array}$ & & & & \\
$\begin{array}{l}\text { Face to face contact } \dagger \\
\text { Telephone support }\end{array}$ & $55.1 \%$ & $66.5 \%$ & $15 \%(3$ to 26$)$ & $9(5$ to 53) \\
& $57.9 \%$ & $59.8 \%$ & $2 \%(-9$ to 12$)$ & $\begin{array}{l}\text { Not } \\
\text { significant }\end{array}$ \\
\hline
\end{tabular}

*Abbreviations defined in glossary; RRR, NNT, and CI calculated from data in article. $†$ Based on a random effects model.

Source of funding: No external funding.

For correspondence:DrJ Sikorski, General Practice and Primary Care, Guy's, King's, and St Thomas' School of Medicine, 5 Lambeth Walk, London SE11 6SP,UK. Fax +44 (0)171 7937232.

A modified version of this abstract appears in Evidence-Based Medicine.

\section{Commentary}

This review by Sikorski and Renfrew examined support for breast feeding mothers and found that it reduced the number of mothers who stopped breast feeding before 2 months postpartum.

The search strategy used to identify studies was thorough. The authors point out the difficulties of comparing the results of trials that have different designs. Pre-set inclusion criteria specified therefore that only randomised or quasi-randomised trials would be included in the analysis. It has been shown that meta-analyses that include less rigorous study designs, such as cohort or case control studies, often show stronger estimates of treatment efficacy than do meta-analyses that include only randomised controlled trials.

Dungy et al claim that maternal attitudes are better predictors of feeding method than are sociodemographic factors, ${ }^{2}$ and therefore knowledge of the mother's level of motivation and intention to breast feed before starting the interventions would give greater meaning to the results.

The World Health Organisation recommended the creation of breast feeding support groups in its 1989 publication, Protecting, Promoting and Supporting Breastfeeding, ${ }^{3}$ and a study that compared traditional postnatal hospital care with early discharge points out the necessity of observing the feeding situation. ${ }^{4}$ The lesson learnt from this review, valuable to all professionals involved in lactation counselling, is the necessity of meeting face to face with mothers to optimise the effects of counselling. Now that the effectiveness of breast feeding support has been shown, we need to find ways to help clinicians to implement appropriate interventions in their own settings. This could be accomplished through careful review of the specific components of the interventions and how they were delivered, and through the development and evaluation of clinical practice guidelines.

$$
\begin{array}{r}
\text { Linda J Kvist, RN, RM, MScN } \\
\text { Midwife } \\
\text { The Women's Clinic, Central Hospital } \\
\text { Helsingborg, Sweden }
\end{array}
$$

1 Colditz GA, Miller J, Mosteller F. Stat Med 1989;8:441-54

2 Dungy CI, Losch M, Russell D.J Assoc Acad Minor Phys 1994;5:159-64.

3 World Health Organisation. Protecting, promoting and supporting breastfeeding. Geneva: WHO, 1989.

4 Kvist LJ, Persson E, Lingman GK. Midwifery 1996;12:85-92. 